\title{
CORRECTION TO: ENHANCEMENT OF AMORPHOUS SILICA DISSOLUTION BY INTERACTION WITH SIX-MEMBERED RING HETEROCYCLIC COMPOUNDS
}

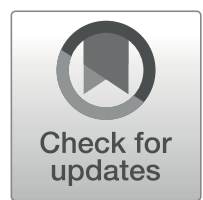

$$
\text { Motoharu KaWANo }{ }^{1} \text { AND JinYEON Hwang }{ }^{2}
$$

${ }^{1}$ Graduate School of Science and Engineering, Kagoshima University, 1-21-35, Korimoto, Kagoshima 890-0065, Japan ${ }^{2}$ Division of Earth Environmental System, Pusan National University, Busan 609-735, South Korea

\section{Correction to: Clays Clay Miner.}

https://doi.org/10.1007/s42860-019-00045-w

This article was updated to fix formatting errors in Eqs. 3, 4 and 5 introduced in the production process.

The online version of the original article can be found at https://doi.org/10.1007/s42860-019-00045-w

* E-mail address of corresponding author: kawano@sci.kagoshimau.ac.jp 